\title{
Theoretical Uncertainty Analysis of Satellite Retrieved Aerosol Optical Depth Associated with Surface Albedo and Aerosol Optical Properties
}

\author{
Jingting Huang 1,2,*D, William Patrick Arnott ${ }^{2}$, James C. Barnard ${ }^{2}(\mathbb{D})$ and Heather A. Holmes ${ }^{1,2}$ \\ 1 Department of Chemical Engineering, University of Utah, Salt Lake City, UT 84112, USA; \\ heather.holmes@chemeng.utah.edu \\ 2 Atmospheric Sciences Program, Department of Physics, University of Nevada-Reno, Reno, NV 89557, USA; \\ arnottw@unr.edu (W.P.A.); jbarnard@unr.edu (J.C.B.) \\ * Correspondence: jingting.huang@utah.edu
}

Citation: Huang, J.; Arnott, W.P.; Barnard, J.C.; Holmes, H.A. Theoretical Uncertainty Analysis of Satellite Retrieved Aerosol Optical Depth Associated with Surface Albedo and Aerosol Optical Properties. Remote Sens. 2021, 13, 344 https://doi.org/10.3390/rs13030344

Received: 31 December 2020

Accepted: 18 January 2021

Published: 20 January 2021

Publisher's Note: MDPI stays neutral with regard to jurisdictional claims in published maps and institutional affiliations.

Copyright: (c) 2021 by the authors. Licensee MDPI, Basel, Switzerland. This article is an open access article distributed under the terms and conditions of the Creative Commons Attribution (CC BY) license (https:// creativecommons.org/licenses/by/ $4.0 /)$.

\begin{abstract}
Deriving aerosol optical depth $(A O D)$ from space-borne observations is still challenging due to uncertainties associated with sensor calibration drift, cloud screening, aerosol type classification, and surface reflectance characterization. As an initial step to understanding the physical processes impacting these uncertainties in satellite $A O D$ retrievals, this study outlines a theoretical approach to estimate biases in the satellite aerosol retrieval algorithm affected by surface albedo and prescribed aerosol optical properties using a simplified radiative transfer model with a traditional error propagation approach. We expand the critical surface reflectance concept to obtain the critical surface albedo (CSA), critical single scattering albedo (CSSA), and critical asymmetry parameter (CAP). The top-of-atmosphere (TOA) reflectance is not sensitive to significant variability in aerosol loading $(A O D)$ at the critical value; thus, the $A O D$ cannot be determined. Results show that $5 \%$ bias in surface albedo $(A)$, single scattering albedo $(S S A)$, or asymmetry parameter $(g)$ lead to large retrieved $A O D$ errors, especially high under conditions when $A, S S A$, or $g$ are close to their critical values. The results can be useful for future research related to improvements of satellite aerosol retrieval algorithms and provide a preliminary framework to analytically quantify $A O D$ uncertainties from satellite retrievals.
\end{abstract}

Keywords: propagation of error; radiative transfer model; satellite remote sensing; air quality

\section{Introduction}

One significant role of atmospheric aerosols in assessing and predicting climate change can be attributed to direct scattering and absorption of solar and terrestrial radiation [1-4]. Accurately quantifying the aerosol direct radiative effects on the Earth's changing energy budget is desired, but it is often particularly challenging [5-7]. Though the mechanism of direct aerosol effects is theoretically well understood [8-10], far greater uncertainties in accessing the contribution of aerosols to the radiative balance are caused by insufficient knowledge concerning physicochemical and optical properties of aerosols as well as surface reflectance characterization [11-13]. Many of these uncertainties arise because aerosols are complex mixtures varying widely across space and time in the atmosphere.

As the importance of aerosols in climate studies has become highly recognized, the level of scientific understanding of the direct aerosol effects has been improved through largely model-based studies [14-18] and increasingly measurement-based estimates [19-23]. In many cases, observations of aerosol optical and microphysical properties are essential tools for radiative transfer calculations, along with inputs from global aerosol models. Unfortunately, long-term and well-characterized in-situ measurements are constrained by achieving comprehensive coverage due to expensive instrumentation [24]. Thanks largely to the advent of the earth observation system (EOS) era, satellite retrievals are the 
only means capable of providing global aerosol products to measure the perturbation of radiative fluxes [25].

Radiative transfer models (RTMs) rely on aerosol information from both the modelbased and measurement-based aerosol monitoring approaches. To describe the extinction magnitude of incident light by aerosols from the surface to the top of the atmosphere (TOA), aerosol optical depth $(A O D)$ has gained attention as one of the most common aerosol products retrieved from spaceborne observations [26,27], which at different spectral wavelengths (mostly in the visible range) helps derive information about other aerosol optical properties and understand their impact on the radiation balance. In an atmospheric solar RTM framework, satellite $A O D$ [21] together with single scattering albedo (SSA) and asymmetry parameter $(g)$, taken from global aerosol models $[28,29]$ or ground-based sunphotometers $[19,20]$, are fundamental inputs to determine the scattering and the absorption of radiation by an aerosol layer. SSA not only largely influences the strength of the aerosolinduced change in TOA radiative balance but also can modify its sign from negative (cooling effect) to positive (warming effect) [30]. Moreover, the variation of $g$ (defined as the cosine-weighted mean of the phase function) from -1 (pure backward scattering) to 1 (pure forward scattering) can provide information about the distribution of scattered radiation [31].

The general RTM techniques are commonly used for the direct calculation of satellite $A O D$ via analytical equations. Several satellite measurement platforms have successfully provided $A O D$ data based on reflected solar radiance measurements using RTM approaches. However, there is a fair amount of uncertainty associated with satellite $A O D$ retrieval algorithms because it is difficult to parameterize fundamental aerosol optical properties (e.g., SSA and $g$ ) effectively for use in RTMs [32]. Wong and Li (2002) [33] explored $A O D$ data from the Advanced Very High Resolution Radiometer (AVHRR) built by ITT Aerospace/Defense Communications in Fort Wayne, IN during heavy wildfire smoke periods across the western U.S. and found the $A O D$ values to be very sensitive to the assumptions made regarding the smoke aerosols due to a knowledge gap related to the optical properties (SSA and $g$ ). The low correlation between NASA MODIS (Moderate Resolution Imaging Spectroradiometer [34] developed by Raytheon Santa Barbara Remote Sensing (SBRS) in Goleta, CA) AOD and ground "truth" NASA AERONET (Aerosol Robotic Network [35] established by NASA and PHOTONS) AOD also lies, in part, in the reliance of aerosol model schemes in the look-up tables (LUT) that prescribe SSA and $g$ in the remote sensing algorithm [36].

Most importantly, acquiring satellite-derived $A O D$ with high accuracy is quite tricky over regions with complex terrain and in arid or semi-arid environments, especially the western U.S. [37,38]. Satellite $A O D$ retrievals are typically overestimated over desert regions because the bright surfaces restrict the retrieval in moderate and low dust loading conditions, and the upwelling radiance due to aerosol loading is small compared to the surface reflectance making it difficult to separate the aerosol signal from the surface contribution [39-41]. It has been found that uncertainty in the surface albedo of $1 \%$ can translate to at least $100 \% A O D$ retrieval error [42]. Concerns about the potential role for the critical surface albedo (CSA) in uncertainty estimates of $A O D$ in remote sensing was first proposed by Fraser and Kaufman (1985) [43] based on radiative transfer simulations. This research suggested that, at the CSA, additional aerosol loading should not generate a net change in the upward radiance since the enhanced aerosol backscattering at the TOA is balanced by the increased attenuation of light by the aerosol layer [44]. Great efforts have been made by exploiting this critical value concept to identify the relationships between CSA and SSA [45-48] and further studying the implications of the CSA in aerosol remote sensing $[38,42,49,50]$.

To the best of our knowledge, it appears that there have been no analytical studies that consider how $A O D$ uncertainties are simultaneously correlated with surface albedo $(A)$, single scattering albedo $(S S A)$, and asymmetry parameter $(g)$ in the satellite retrieval algorithms. Our work builds on the CSA concept and considers the $A O D$ sensitivity to the 
critical surface albedo (CSA), the critical single scattering albedo (CSSA), and the critical asymmetry parameter (CAP). The CSA, CSSA, and CAP are respectively defined as the values of surface albedo, single scattering albedo, and asymmetry parameter where the TOA reflectance is independent of the $A O D$ value. While investigating the CSSA and CAP does not provide as useful information as the CSA, these parameters included in our model are also essential to providing an analytical method to quantify uncertainties in these variables on the $A O D$ values obtained from satellites. The CSSA and CAP play a crucial role when values are prescribed in the RTM from the LUT, and the aerosol type may not align with the actual aerosol type, or realistic aerosol mixture, in the atmosphere. We use a simplified radiative transfer model to analytically determine the CSA, CSSA, and CAP through the propagation of error approach that results in the partial derivatives of $A O D$ with respect to $A, S S A$, and $g$. Furthermore, to elucidate the importance of the uncertainties in $A, S S A$, and $g$ on $A O D$, we determine the CSA, CSSA, and CAP using multiple aerosol models. At or near these critical values, the uncertainty in $A O D$ retrievals is considerable because a change in $A O D$ has almost no influence on the TOA reflectance. Additionally, these critical values are where the aerosol forcing changes sign. This approach also allows us to investigate the physical characteristics related to surface albedo and aerosol optical properties that lead to uncertainties in $A O D$ retrievals.

Understanding and quantifying the $A O D$ uncertainties from satellite remote sensing platforms is critical in improving the global estimates of $A O D$. Previous methods have been used to quantify these uncertainties; however, many of them face limitations. A common, well-accepted approach to determine the retrieval error of satellite $A O D$ datasets is the comparison of satellite measurements and ground-based sensor data [51-54]. While this approach is meaningful, it should be regarded as an evaluation of the retrieval algorithm rather than an uncertainty analysis [55]. Knapp et al. (2002) [56] used an ensemble approach with numerous $A O D$ retrieval simulations and summarized the retrieval uncertainties of satellite $A O D$ to be $18 \%$ to $34 \%$, depending upon the certainty of the assumed radiative transfer model parameters. Sayer et al. (2013) [57] defined retrieval-level absolute uncertainties of satellite $A O D$ products by formulating a linear relationship $(a+b \tau)$ between uncertainties in modeled surface reflectance (a), assumptions about aerosol microphysical properties made in the retrieval algorithm (b) and satellite $A O D$ at $550 \mathrm{~nm}(\tau)$. Still, in essence, this empirical model was obtained in terms of an absolute error of the satellite $550 \mathrm{~nm}$ AOD compared to AERONET AOD. The error calculation in Sayer et al. (2013) [57] is only applicable for cases where there are AERONET sensors, and physical processes do not stratify the uncertainties in satellite $A O D$, so it is unrealistic to determine the sensitivity of $A O D$ to $A, S S A$, and $g$ using this approach.

Our overarching study goal is to provide an initial framework to better understand satellite $A O D$ retrieval uncertainties associated with surface albedo, single scattering albedo, and asymmetry parameter. Other important factors to consider in $A O D$ uncertainties using satellite retrieval algorithms are solar geometry and satellite viewing angle [25,58-60]. However, the simplified model proposed here does not account for changes in either of these variables. This paper proposes a 1-D fast and simple radiative transfer model and emphasize the use of traditional error propagation to quantify the uncertainty estimates for inclusion in satellite $A O D$ algorithms according to well-understood perturbations (i.e., surface variations and uncertainties in aerosol optical properties). The two main research objectives of this study are: (1) outline the importance of the CSA, CSSA, and CAP concepts in next-generation satellite $A O D$ products to the scientific user community; (2) elaborate on a mathematical and physical framework to compute uncertainties in satellite $A O D$ retrievals using analytical equations.

\section{Model Development}

To derive our fast and simple atmospheric solar 1-D radiative transfer model, we need to consider that a sensor is above the TOA looking down toward the surface in the case of normal illumination where 3-D effects (i.e., horizontal transport of photons) 
and polarization are ignored. We use the propagation of error approach [61] to quantify the uncertainty of aerosol optical depth concerning the uncertainty of surface albedo $(A)$, single scattering albedo of aerosols (SSA), and asymmetry parameter $(g)$. Here $A, S S A$, and $g$ are independent variables (neglecting their correlations for simplicity). Our model makes simplifying assumptions: (1) the atmosphere is one-dimensional, and it varies only in the vertical direction while horizontal variations are neglected; (2) the aerosol layer is infinitesimally thin and is in a plane-parallel, uniform atmosphere under clear-sky conditions; (3) both Rayleigh (e.g., at $660 \mathrm{~nm}, \sim 0.04)$ and aerosol optical depth $(<0.1)$ are far less than unity, which requires the aerosol layer to be optically thin enough so that the single-scattering approximation is valid.

The development of this model is motivated by the desire to investigate the impact of surface reflectance on satellite $A O D$ retrievals, described by Boehmler et al. (2018) [38], in the atmosphere with a limited amount of scattering. A general mathematical framework for the application of atmospheric solar radiative transfer in a simplified 1-D scene is presented in this study (see Figure 1) to calculate the sensitivity of $A O D$ to surface reflectance $(A)$, single scattering albedo (SSA), and asymmetry parameter $(g)$. The purpose of this model is to provide an analytical expression for quantifying and understanding the uncertainty in $A O D$ retrievals as a function of surface albedo $(A)$ and aerosol optical properties (e.g., SSA and $g$ ) using the propagation of error approach.

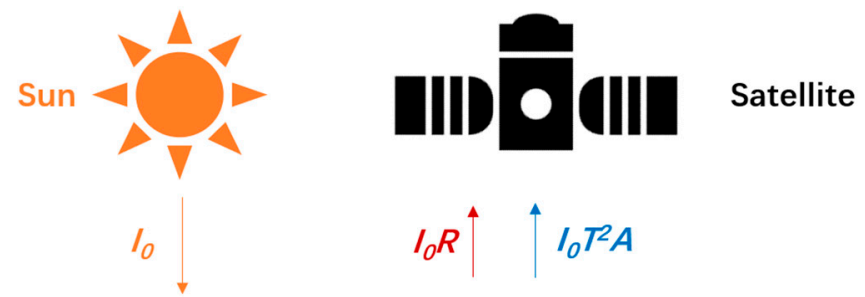

Aerosol Layer

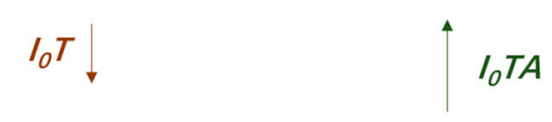

Surface

Figure 1. Schematic diagram of the 1-D radiative transfer model. $I_{0}$ is the top of the atmosphere solar irradiance, $A$ is the surface albedo, $T$ is the fraction of total radiation (diffuse and direct) transmitted through the aerosol layer, and $R$ is the fraction of the incident beam backward scattered by the aerosol layer. $I_{0} R$ is the backscattered radiation by the aerosol layer and $I_{0} T^{2} A+I_{0} T^{2} A^{2} R$ is the sum of the direct and diffuse radiation caused by aerosols.

This work aims to investigate this key question: How do we identify trends in performance degradation from satellite $A O D$ retrievals caused by the gradual shift in three parameter values $(A, S S A, g)$ from their true values? The analytical solution proposed here is used to obtain the partial derivatives- $\partial A O D / \partial A, \partial A O D / \partial S S A$, and $\partial A O D / \partial g$ so that we can determine uncertainty estimates within satellite $A O D$ datasets as it relates to the uncertainty in surface albedo $(\triangle A)$, single scattering albedo $(\triangle S S A)$, and asymmetry parameter $(\Delta g)$ :

$$
\Delta A O D=\sqrt{\left(\Delta A\left(\frac{\partial A O D}{\partial A}\right)\right)^{2}+\left(\Delta S S A\left(\frac{\partial A O D}{\partial S S A}\right)\right)^{2}+\left(\Delta g\left(\frac{\partial A O D}{\partial g}\right)\right)^{2}} .
$$

We adopt two-stream approximations for solar radiation transfer through one planeparallel uniform scattering layer (e.g., an aerosol layer) in the atmosphere. This singlescatter model makes less restrictive assumptions regarding the nature of the radiance field and scattering phase function but does not incorporate second- or higher-order terms of the radiance field into the solution. Thus, this approach is only directly applicable 
under weak scattering conditions (i.e., minimal scattering optical depth). We define the satellite-received total radiation $I_{\text {tot }}$ as

$$
I_{\text {tot }}=I_{1}+I_{2}
$$

where $I_{1}$ is the backscattered radiation by the aerosol layer, and $I_{2}$ is the sum of the direct beam radiation reflected by the surface and the diffusely scattered radiation due to 2-times forward scattering from the presence of aerosol in the atmosphere affected by the surface. $I_{1}$ is given by

$$
I_{1}=I_{0} R,
$$

where $I_{0}$ is the TOA solar irradiance and $R$ is the fraction of the incident beam backward scattered by the aerosol layer. $R$ is given by

$$
R \cong S S A \cdot A O D \cdot \frac{1-g}{2}
$$

and $I_{2}$ is given by

$$
I_{2}=I_{0} T^{2} A+I_{0} T^{2} A^{2} R,
$$

where $T$ is the fraction of total radiation (diffuse and direct) transmitted through the aerosol layer. $T$ is given by

$$
T \cong(1-A O D)+S S A \cdot A O D \cdot \frac{1+g}{2} .
$$

By neglecting high order terms in AOD, $T$ to the second power with Taylor series approximation is given by

$$
\begin{aligned}
T^{2} & \cong\left((1-A O D)+S S A \cdot A O D \cdot \frac{1+g}{2}\right)^{2} \\
& \cong(1-2 A O D+S S A \cdot A O D \cdot(1+g))
\end{aligned}
$$

Thus,

$$
I_{\text {tot }} \cong I_{0}\left[\left(1+A^{2}\right) S S A \cdot A O D \cdot \frac{1-g}{2}+(1-2 A O D) A+S S A \cdot A O D \cdot A(1+g)\right] \text {. }
$$

To solve Equation (8) for $A O D$, the total spectral reflectance at TOA, $\gamma$ is defined by

$$
\gamma=\frac{I_{t o t}}{I_{0}} \sim \text { const }
$$

where $\gamma$ is the ratio of the total radiation received by the satellite to the top of the atmosphere solar irradiance. Substituting Equation (9) into Equation (8), and solving for $A O D$,

$$
A O D \cong \frac{\gamma-A}{\left[\left(1+A^{2}\right) S S A \frac{1-g}{2}+A(S S A(1+g)-2)\right]} .
$$

Starting with Equation (10) and taking the partial derivatives of $A O D$ with respect to $A, S S A$, and $g$ [61], and then using Equation (9) for $\gamma$ gives (where $A O D<0.1$ ),

$$
\left\{\begin{array}{l}
\frac{\partial A O D}{\partial A} \cong \frac{1}{\left[2 A\left(1-S S A \frac{1+g}{2}\right)-\left(1+A^{2}\right) S S A \frac{1-g}{2}\right]} \\
\frac{\partial A O D}{\partial S S A} \cong-\frac{A O D}{S S A-\frac{2 A}{\left(1+A^{2}\right) \frac{1-g}{2}+A(1+g)}} \\
\frac{\partial A O D}{\partial A} \cong \frac{A O D}{\frac{\left(1+A^{2}\right) \frac{1-g}{2}+A\left[(1+g)-\frac{2}{S S A}\right]}{\frac{1+A^{2}}{2}-A}}
\end{array}\right.
$$


We further analytically quantify the total uncertainty in $A O D$ in terms of $A, S S A$, and $g$, based upon propagation of error by substituting the results from the above Equation (11) back into Equation (1):

$$
\begin{aligned}
& \Delta A O D=\sqrt{\left(\Delta A\left(\frac{\partial A O D}{\partial A}\right)\right)^{2}+\left(\Delta S S A\left(\frac{\partial A O D}{\partial S S A}\right)\right)^{2}+\left(\Delta g\left(\frac{\partial A O D}{\partial g}\right)\right)^{2}} \\
& =\sqrt{\left(\Delta A\left(\frac{1}{\left[2 A\left(1-S S A \frac{1+g}{2}\right)-\left(1+A^{2}\right) S S A \frac{1-g}{2}\right]}\right)\right)^{2}+\left(\Delta S S A\left(-\frac{A O D}{S S A-\frac{2 A}{\left(1+A^{2}\right) \frac{1-g}{2}+A(1+g)}}\right)\right)^{2}+\left(\Delta g\left(\frac{A O D}{\frac{\left(1+A^{2}\right) \frac{1-g}{2}+A\left[(1+g)-\frac{2}{S S A}\right]}{\frac{1+A^{2}}{2}-A}}\right)\right)^{2}} .
\end{aligned}
$$

Taking the limits of Equation (11), first notice that $\partial A O D / \partial A \rightarrow \infty, \partial A O D / \partial S S A \rightarrow \infty$ and $\partial A O D / \partial g \rightarrow \infty$ when their denominators in Equation (11) are set equal to zero to find a critical value of surface albedo $(A)$, single scattering albedo $(S S A)$, and asymmetry parameter $(g)$,

$$
\left\{\begin{array}{c}
A_{\text {crit }}=\frac{2-S S A(1+g) \pm 2 \sqrt{1+S S A[g(S S A-1)-1]}}{S S A(1-g)} \\
S S A_{\text {crit }}=\frac{2 A}{\left(1+A^{2}\right) \frac{1-g}{2}+A(1+g)} \\
g_{\text {crit }}=\frac{S S A(1+A)^{2}-4 A}{S S A(1-A)^{2}}
\end{array}\right.
$$

Note that in Equation (11a) the TOA reflectance (i.e., $\gamma=\frac{I_{\text {tot }}}{I_{0}}$ ) has a non-linear relationship with surface albedo, which means there are two roots for solving for the critical surface albedo [see Equation (13a)]. However, the value of surface albedo should range from 0 to 1 . The first solution of $A_{\text {crit }}\left(\right.$ i.e., $\left.\frac{2-S S A(1+g)+2 \sqrt{1+S S A[g(S S A-1)-1]}}{S S A(1-g)}\right)$ is always greater than 1 when $S S A, g \in(0,1)$. In this case, we used the second solution of $A_{\text {crit }}\left(\right.$ i.e., $\left.\frac{2-S S A(1+g)-2 \sqrt{1+S S A[g(S S A-1)-1]}}{S S A(1-g)}\right)$ to investigate the sensitivity of TOA reflectance to $A O D$.

Now, we will briefly discuss the physical interpretation of the theoretical model. Since $\gamma=\frac{I_{\text {tot }}}{I_{0}}$ we find that

$$
\gamma \cong A O D\left[(1+A)^{2} S S A \frac{(1-g)}{2}-A(2-S S A(1+g))\right]+A .
$$

When the first term in Equation (14) goes to 0 , then $\gamma \cong A$. Here $A$ is equal to $A_{\text {crit }}$. Thus, the physical meaning of critical surface albedo can be explained as a circumstance when aerosol backscatter $(1+A)^{2} S S A \frac{(1-g)}{2}$ counterbalances the net loss due to forward scattering $(A(2-S S A(1+g)))$. Or we can arrange Equation (14) as

$$
\gamma \cong A O D\left[(1+A)^{2} S S A \frac{(1-g)}{2}+A \cdot S S A(1+g)-2 A\right]+A .
$$

Alternatively, another physical meaning of critical surface albedo is to strike a balance between diffuse radiation adding to TOA radiance $\left(A O D(1+A)^{2} S S A \frac{(1-g)}{2}+A O D\right.$. $A \cdot S S A(1+g))$ and the loss of TOA radiance due to the interaction between the direction beam with the surface disturbance $(2 A O D \cdot A)$.

\section{Model Limitations}

The fundamental assumption for the validity of the 1-D radiative transfer model, provided single scattering of the detected photons, is that no scattered photon that leaves the geometrical field of view of the receiver will be detected by neglecting all possible successive orders of scattering contributions. Multiple-scattering media have high albedo (at visible wavelengths) because incident photons reemerge after having been scattered 
many times by particles that are only weakly absorbing. For a sufficiently large optical depth of aerosols (when $A O D>>1$ ), the thick aerosol layer will experience multiple scattering events that cannot be ignored. During high- $A O D$ conditions, our simplified 1-D radiative transfer model would not be applicable in evaluating the uncertainties of $A O D$ from satellite retrievals.

The model assumptions here require that the $A O D$ values be much less than 1 to account for neglecting high order terms in $A O D$ in the mathematical model. Thus, our study emphasizes conditions where $A O D \leq 0.1$. There are many time periods in regions with low air pollution emissions that have total aerosol loadings that would be within the assumed limits of our radiative transfer model. For example, Figure 2a shows the spectral variation of measured AOD (340-1064 nm) from AERONET at the University of Nevada, Reno (UNR) on 17 October 2019. From 5:00 p.m. to 12:00 a.m., the AERONET AOD data is far smaller than one for all wavelengths. Whereas, Figure $2 b$ shows daily $A O D$ values $(0.1<A O D<0.3)$ that are higher than the previous example at smaller wavelengths on 1 October-20 October 2019. The retrieval of $A O D$ at wavelengths shorter than $500 \mathrm{~nm}$, in this case, would have significant uncertainties using our simple 1-D radiative model since both the Rayleigh ( $\sim 0.1)$ and aerosol optical depth $(>0.1)$ are outside the limits of our initial model assumptions. The $800 \mathrm{~nm}$ thus was picked as a representative wavelength to demonstrate the model results. Though the $A O D$ range within 0.1 considered in our model is small, low- $A O D$ cases, in fact, match the global average $A O D$ value [57].

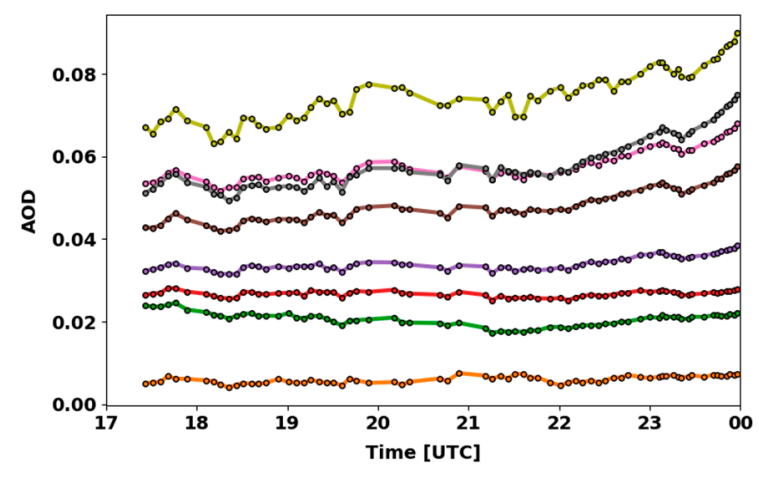

(a)

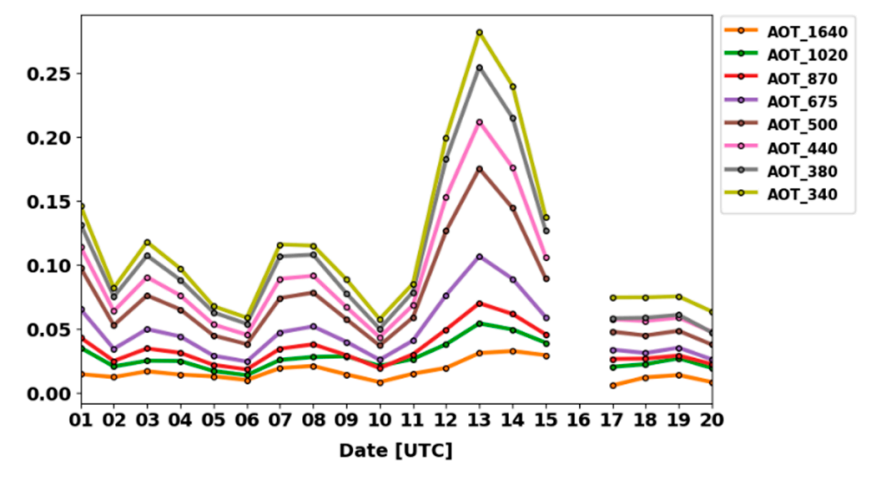

(b)

Figure 2. (a) Time series of spectral $A O D$ measurements (AERONET Level 1.5) at the UNR site $\left(39.541^{\circ} \mathrm{N}, 119.814^{\circ} \mathrm{W}\right)$ on 17 October 2019 (left); (b) Time series of spectral AOD measurements at the UNR site during 2019 October at wavelengths from $340 \mathrm{~nm}$ to $1640 \mathrm{~nm}$ (right).

\section{Aerosol Models}

Numerous studies have focused on measuring and interpreting aerosol optical proprieties [62-66], and their findings can be used in an RTM to approximate the aerosol conditions in the atmosphere. We consider several generalized categories for aerosol types with distinctly different optical properties to evaluate the models of representative aerosols. To use our 1-D radiative model and examine the impacts of aerosol properties on $A O D$ retrievals, we pick five different aerosol models defined by the OPAC (Optical Properties of Aerosols and Clouds) software package [67]. Given the single scattering approximation in our 1-D radiative transfer model, we use the aerosol model properties at $800 \mathrm{~nm}$ as the representative wavelength to satisfy the constraint on aerosol loading (i.e., $A O D<<1$ ), by assuming $50 \%$ relative humidity and externally mixed typical aerosol components to form aerosol types.

The following is a brief description of the five aerosol types obtained from OPAC [64]: (1) the continental clean aerosol represents remote continental locations with no or little anthropogenic influence; (2) the continental average aerosol comes from anthropogenically influenced continental areas; (3) the continental polluted aerosol depicts highly polluted 
continental (not urban) areas heavily influenced by anthropogenic emissions; (4) the urban aerosol is used to describe strong pollution from fossil fuel combustion in densely populated industrial areas; (5) the desert aerosol made up of mineral dust over all deserts of the world with no local distinction. These five general aerosol types are associated with different sources and emission mechanisms and are expected to exhibit significant differences in aerosol optical properties. A shortlist of these properties is given in Table 1. We use the properties in the 'total' row for each aerosol type.

Table 1. Microphysical and optical properties of the aerosol models grouped by aerosol types and aerosol components, with OPAC values for the number densities $\left(\mathrm{N}_{\mathrm{i}}\right)$ of aerosol components in particles $\mathrm{cm}^{-3}$, single scattering albedo $(S S A)$ and asymmetry parameter $(g)$ at a wavelength of 0.8 micrometers for $50 \%$ relative humidity.

\begin{tabular}{ccccc}
\hline Aerosol Types & Components & $\mathbf{N}_{\mathbf{i}} \mathbf{( \mathbf { c m } ^ { - 3 } )}$ & $\mathbf{S S A}$ & $\mathbf{g}$ \\
\hline \multirow{4}{*}{ Continental clean } & total & 2600 & 0.933 & 0.655 \\
& water soluble & 2600 & 0.956 & 0.634 \\
& insoluble & 0.15 & 0.777 & 0.797 \\
\hline \multirow{4}{*}{ Continental average } & total & 15,300 & 0.861 & 0.620 \\
& water soluble & 7000 & 0.956 & 0.634 \\
& insoluble & 0.4 & 0.777 & 0.797 \\
Continental polluted & soot & 8300 & 0.135 & 0.266 \\
& total & 50,000 & 0.812 & 0.588 \\
& water soluble & 15700 & 0.956 & 0.634 \\
& insoluble & 0.6 & 0.777 & 0.797 \\
& soot & 34,300 & 0.135 & 0.266 \\
\hline Urban & total & 158,000 & 0.711 & 0.545 \\
& water soluble & 28,000 & 0.956 & 0.634 \\
& insoluble & 1.5 & 0.777 & 0.797 \\
& soot & 130,000 & 0.135 & 0.266 \\
\hline Desert & total & 2300 & 0.922 & 0.703 \\
& water soluble & 2000 & 0.956 & 0.634 \\
& mineral (nuc. mode) & 269.5 & 0.977 & 0.633 \\
& mineral (acc. mode) & 30.5 & 0.932 & 0.7 \\
& mineral (coa. mode) & 0.142 & 0.754 & 0.854 \\
\hline
\end{tabular}

\section{Results}

\subsection{RTM Results}

Under the single scattering assumption, we generate a synthetic dataset of TOA reflectance with multiple values of single-scattering albedo, asymmetry parameter, surface albedo, and $A O D$ values ranging from 0 to 0.1 at $800 \mathrm{~nm}$. Aerosol optical parameters from the five different aerosol modes are used in the radiative transfer equations to calculate uncertainties and critical parameters. According to Equation (13), we get the critical value of one of the three variables $(A, S S A$, and $g$ ) when given the other two. For a given aerosol of fixed $S S A$ and $g$ (e.g., from Table 1), there is a specific surface albedo, namely CSA, at which the TOA reflectance is nearly insensitive to aerosol loading based on Equation (13a). Because we are unable to analyze the CSSA or CAP using surface albedo measurements from ground observations or satellite remote sensing data, we must rely on another method to obtain the CSSA or CAP. A shortcut to get the critical values for the aerosol properties is to rely on the CSA calculated in the way mentioned above, using it as the input surface albedo while assuming only one of modeled aerosol values (i.e., SSA or $g$ ) since we are able to obtain these aerosol optical properties given a specific aerosol type (from Table 1). Then we compute the CSSA[CAP] by substituting the CSA and $g[S S A]$ into Equation (13b) [(13c)]. Table 2 gives a summary of the CSSA, CAP, and CSA values for the different aerosol classes according to this special situation. The CSA values in Table 2 are computed from the aerosol types using the specific SSA and $g$ listed in Table 1. The CSSA and CAP are 
included in Table 2 for clarity, but are the same as the SSA and g values in Table 1 due to the shortcut method used for calculating the CSSA and CAP where the surface albedo is assumed to be equal to the CSA since measurements are not available. It is important to note that these critical values of $S S A$ and $g$ are crucial because they are associated with the CSA. Location-specific albedo measurements are required to calculate the appropriate CSSA and CAP values related to the observed albedo.

Table 2. Summary of CSA, CSSA, CAP values for the five different aerosol types listed in Table 1.

\begin{tabular}{cccc}
\hline Aerosol Type & CSA & CSSA & CAP \\
\hline Continental clean & 0.413 & 0.933 & 0.655 \\
Continental average & 0.294 & 0.861 & 0.62 \\
Continental polluted & 0.25 & 0.812 & 0.588 \\
Urban & 0.186 & 0.711 & 0.545 \\
Desert & 0.36 & 0.922 & 0.703 \\
\hline
\end{tabular}

In Figure S1 (Supplementary Materials), the modeled TOA reflectance is a function of surface albedo $(A)$, single scattering albedo $(S S A)$, and asymmetry parameter $(g)$ for a continental clean (a), continental average (b), continental polluted (c), urban (d), or desert (e) aerosol model stratified by $A O D$ values. Different values of $A O D$ and the selection of aerosol models both influence the TOA reflectance. However, critical values (the CSA, CSSA, and CAP) for the different aerosol types are based on the same principle that the TOA reflectance is almost insensitive to $A O D$. Note that the low sensitivity of the TOA reflectance with respect to $A O D$ as a function of $A$ shown in Figure S1 (Supplementary Materials) illustrates that within the narrow range of $A O D$ values considered in this study, it is virtually imperceptible to spot the CSA in the figure. However, there is still a CSA that makes an inflection point and causes large uncertainties in the $A O D$ values, as we describe below in Section 5.2, even at this low AOD range.

Equation (14) can explain why the CSA of the example aerosol models here are the same as the amount of the TOA reflectance (i.e., $\gamma=$ CSA) because the contribution part of aerosol backscatter $\left(\frac{S S A(1-g)}{2}\right)$ balances the net loss of aerosol radiance due to forward scattering $(S S A(1+g))$. The TOA reflectance for a continental clean aerosol model, subplot (a) in Figure S1 (Supplementary Materials), becomes independent of $A O D$ at a surface albedo of 0.413 , which we define as the CSA where both processes (forward and backward scattering) compensate each other. The distribution of CSA depends on the aerosol absorption ratio (i.e., $S S A$ ) and the aerosol type. As shown in Table 2, the more scattering the aerosol, the larger value of CSA. At the CSA, there is a reversal of the TOA reflectance concerning the aerosol loading, indicating that the TOA reflectance decreases with increasing $A O D$ for brighter surfaces (when surface albedo is larger than the critical value) but increases with increasing $A O D$ for dark surfaces (when surface albedo is smaller than the critical value). This is because aerosol absorption dominates over aerosol scattering if the atmosphere is sufficiently illuminated from below and vice versa $[43,44]$.

The CSSA and CAP, as seen from Figure S1 (Supplementary Materials), are associated with the inherent optical properties of the selected aerosol models. Using the three different continental aerosol models (see Figure S1a-c (Supplementary Materials)), we can investigate how the absorbing properties of aerosols impact the TOA reflectance. The higher fraction of absorbing aerosols in the aerosol model, the more distinct increases in TOA reflectance with increasing $A O D$ (when the single scattering albedo is larger than the critical value), and vice versa, which is attributable to their lower CSSA. However, the TOA reflectance decreases if the amount of aerosol loading increases (when the asymmetry parameter is larger than the critical value) due to the increased forward-scattering fraction of light caused by additional aerosols, and the opposite situation is also true. This illustrates the influence of the aerosol properties on the AOD sensitivity to the TOA reflectance. Absorbing aerosol types have a much lower CSA and CSSA. For instance, the urban model with a very low $S S A$ of 0.711 has a CSA of 0.186 , while the desert model with an $S S A$ of 
0.922 has a CSA value of 0.36 . Moreover, the desert aerosol model with more absorbing aerosol species (e.g., desert dust) compared to the continental clean aerosol model exhibits a higher CAP. The desert aerosol model has more large particles, so the forward scattering probability for the particles is increased.

Though a simplified form of the 1-D radiative transfer model is used in this paper, the results are comparable to previous investigations that used more sophisticated models. For example, Figure S1c,d (Supplementary Materials) and Figure 3c,d in this paper are consistent with Figures 2c, 3b, and 9a,c in Seidel and Popp (2012) [42], respectively, where their studies are based on the Second Simulation of a Satellite Signal in the Solar Spectrum (6S) radiative transfer model. Due to these similarities, the proposed 1-D radiative transfer model presented in this paper captures the underlying physical system behind the overall radiative effects of aerosols, even if the successive higher-order scattering is neglected. Therefore, this analytical approach provides a useful method to quantify uncertainties in $A O D$ remote sensing by a first-order approximation.

\subsection{AOD Uncertainty Analysis}

The simplified RTM offers insight into investigating errors in retrieved $A O D$ associated with physical processes quantitatively. It is helpful to start with a conceptual description of the $A O D$ errors related to the critical values of $A, S S A$, and $g$. The TOA reflectance remains constant at the CSA, CSSA, or CAP despite increasing or decreasing AOD; therefore, satellite sensors are unable to retrieve the correct aerosol signal at the CSA, CSSA, or CAP. Similarly, when parameters $A, S S A$, or $g$ approach their critical values (CSA, CSSA, or $\mathrm{CAP})$, large uncertainties arise in the retrieved $A O D$. At these critical values, there is also a change in the sign of the $A O D$ uncertainty, related to the over- or under-estimation of retrieved $A O D$, an important distinction when using $A O D$ to estimate global air pollution exposure and health impacts. This section focuses on using an analytical framework to quantify retrieval-level $A O D$ uncertainty on a constant assumed error in the related physical quantities $(A, S S A$, and $g)$.

The $A O D$ retrieval errors as a function of surface albedo $(A)$, single scattering albedo $(S S A)$, and asymmetry parameter $(g)$ with an 0.05 under- (marked as the blue minus symbols) and over-estimation (marked as the red plus symbols) of each corresponding properties $(A, S S A$, and $g$ ) for different aerosol types are shown in Figure 3 . This error is defined as the difference between the 'true' $A O D$ and the satellite retrieved $A O D$ (i.e., $\triangle A O D=A O D_{\text {true }}-A O D_{\text {retrieved }}$ ), where the negative (positive) error is the overestimated (underestimated) retrieved $A O D$. A 0.05 deviation of $A, S S A$, or $g$ from their true values illustrates these parameters' influence on the under- and over-estimation of $A O D$. In Figure 3, we set the 'true' $A O D$ to 0.08 , and the curves were calculated using Equation (11). Figure 3 shows that it is impossible to retrieve $A O D$ from satellite remote sensing under conditions at or close to the critical values because the uncertainty of $A O D$ is infinite. This can be seen on the curves where the $A O D$ retrieval errors approach infinity near the CSA, CSSA, and CAP (indicated by the vertical black dashed lines). For example, for the continental clean aerosol model (in Figure 3a), if the actual aerosol $S S A$ is 0.7 and the critical $S S A$ is 0.933 , a $\pm 5 \%$ error in the $S S A$ would results in small $A O D$ retrieval errors because the actual $S S A$ is far from the critical $S S A$. However, as one gets close to the critical $S S A$, a $\pm 5 \%$ error of $S S A$ will induce a much larger error in the $A O D$ retrieval. In contrast, if the simulated errors of surface albedo, single scattering albedo, and asymmetry parameter are small, say within a $\pm 5 \%$ interval, the retrieved $A O D$ errors will be small, provided that the actual surface albedo, single scattering albedo, and asymmetry parameter are far enough away from their critical values (i.e., CSA, CSSA, and CAP). 
As shown in Figure 3, for surface albedo less than the CSA, overestimating the surface albedo will result in an underestimated $A O D$, that is, a positive retrieval error in this example. However, when it comes to the positive departure of surface albedo from the CSA, a negative retrieval error of the surface albedo value will introduce an overestimated $A O D$. Likely, for single scattering albedo smaller (larger) than the CSSA or asymmetry parameter smaller (larger) than the CAP, an overestimation of the single scattering albedo or asymmetry parameter turns out to be an overestimation (underestimation) of $A O D$ and therefore a negative (positive) retrieval error. This behavior can be seen for the single scattering albedo and asymmetry parameter impacts on the $A O D$ errors indicated by the curves for each aerosol model in Figure 3.

An interesting finding is that for the urban aerosol model with strong absorption characteristics (see Figure 3d), quite low $A O D$ retrieval errors are noticeable over extremely bright surfaces provided an aerosol retrieval algorithm that does not rely on the surface being darker than the aerosol [68]. This is an indication that higher reflectance surfaces, such as those covered by fresh snow and ice, will promise a more accurate satellite retrieved $A O D$ of strongly absorbing aerosols (e.g., black carbon). The concern for very bright desert regions, a major natural source of desert dust, is having a surface albedo near the CSA but without available accurate satellite $A O D$ measurements [38,47]. Understanding the CSA might improve both $A O D$ and SSA retrievals in arid and semi-arid environments and would offer an incentive to carefully evaluate albedo products for bright surfaces derived from remote sensing data.
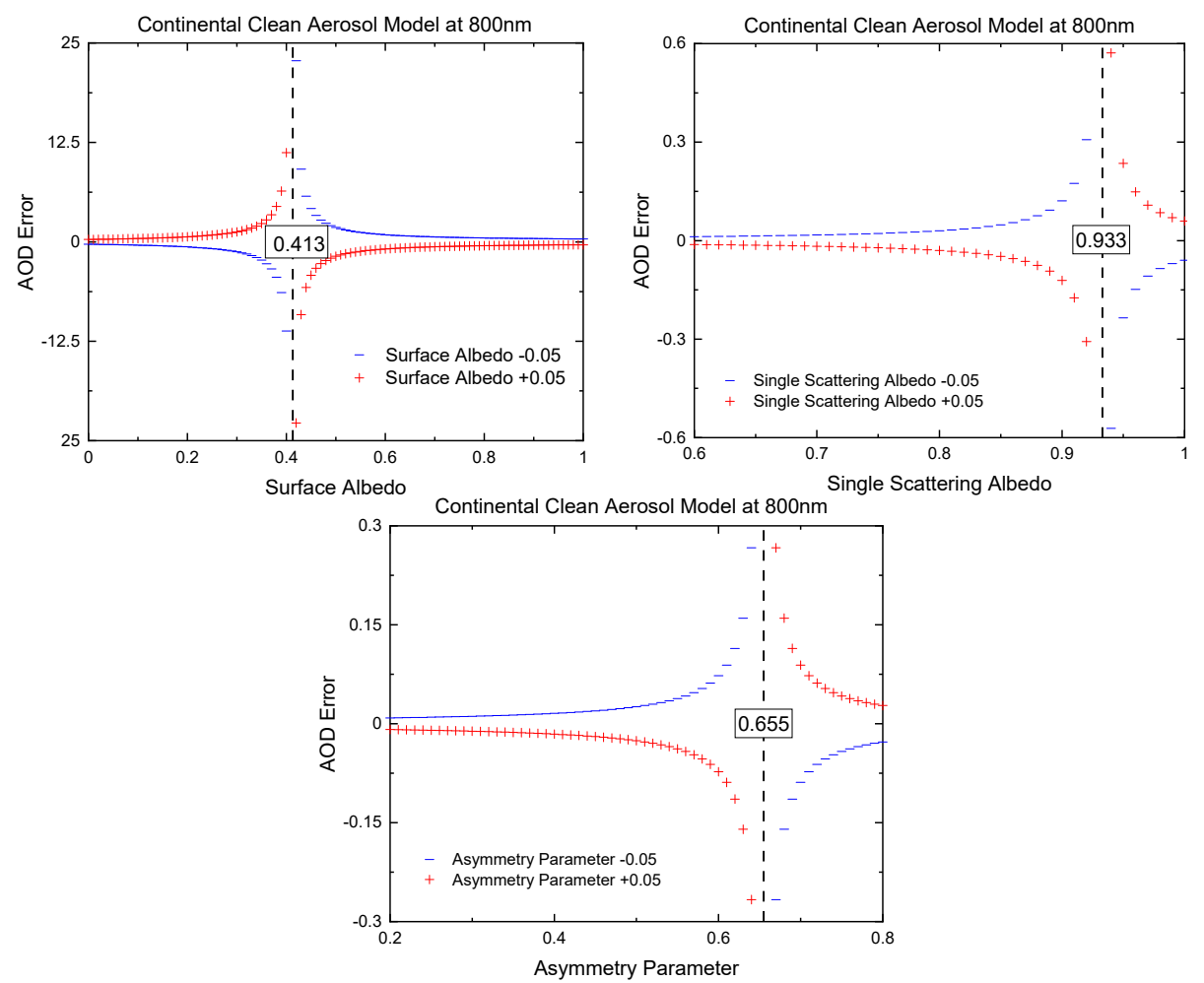

(a)

Figure 3. Cont. 

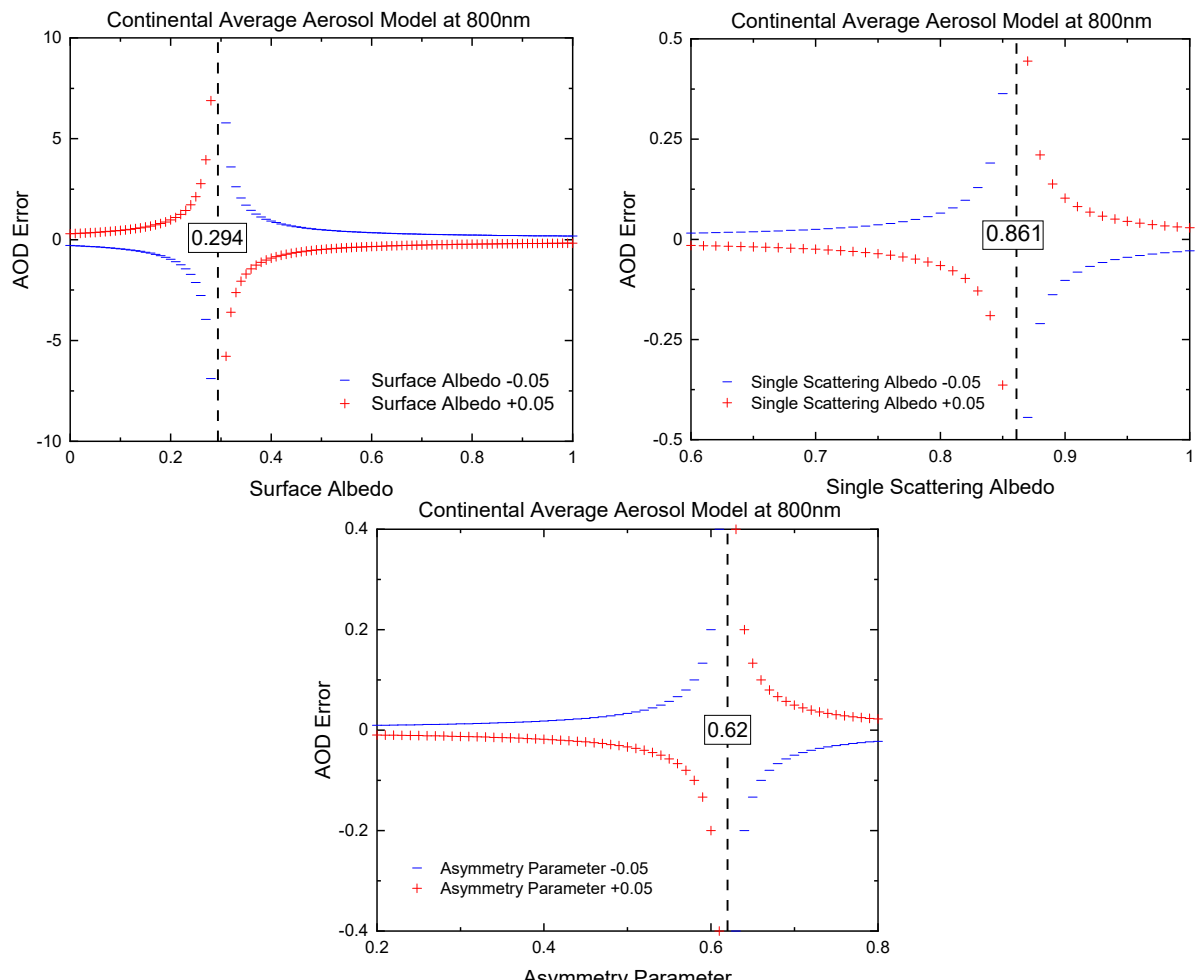

(b)
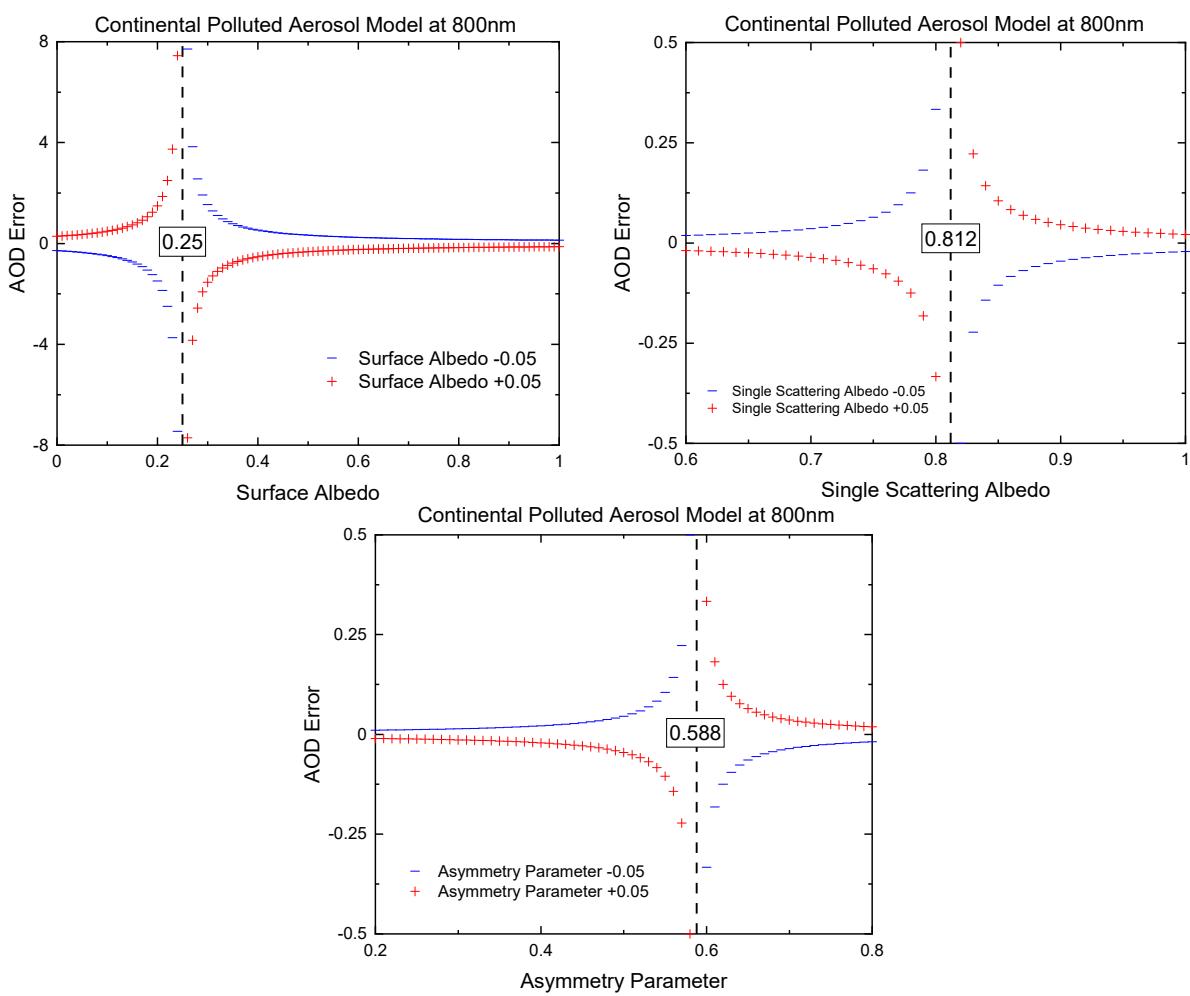

(c)

Figure 3. Cont. 

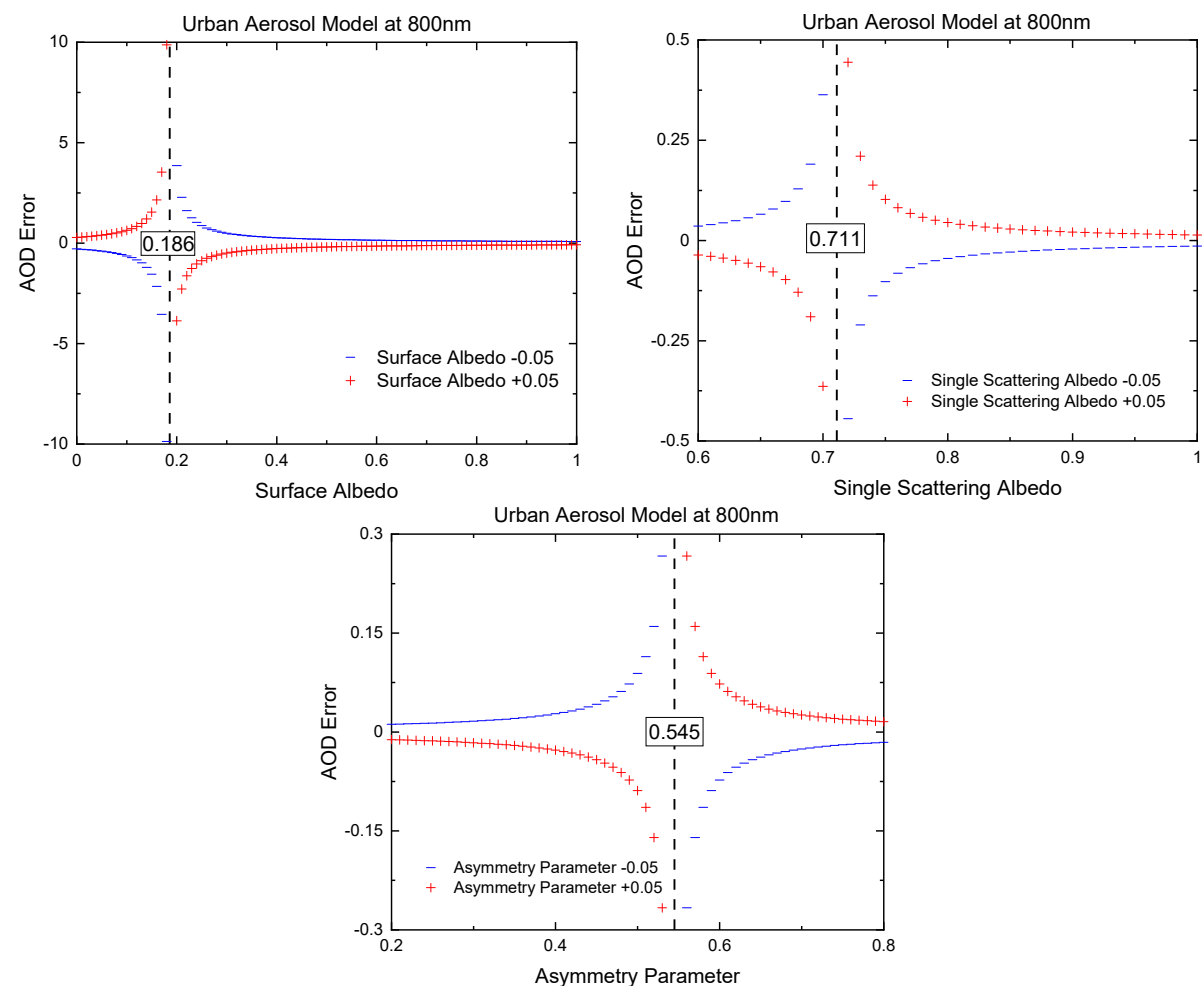

(d)
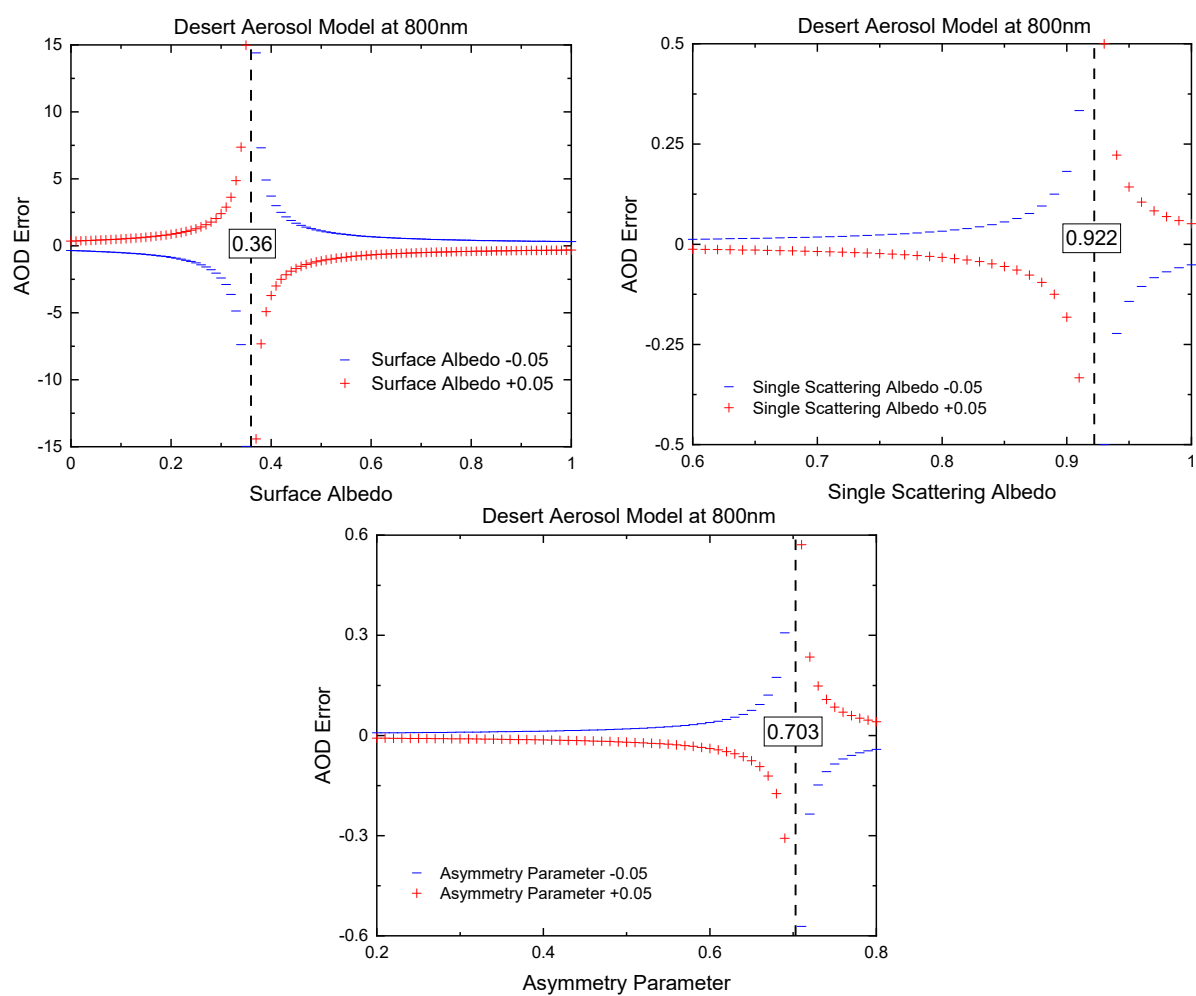

(e)

Figure 3. $A O D$ errors for an $A O D$ of 0.08 as function of surface albedo (top left), single scattering albedo (top right) and asymmetry parameter (bottom) for a continental clean (a), continental average (b), continental polluted (c), urban (d) or desert (e) aerosol model at the wavelength of $800 \mathrm{~nm}$. The red plus sign denotes an overestimation of surface albedo (single scattering albedo or asymmetry parameter) by +0.05 and the blue minus sign denotes an underestimation of surface albedo (single scattering albedo or asymmetry parameter) by -0.05 . The critical values are given in the box along with the dashed line. 


\subsection{Real World Case Study}

Nevada's Black Rock Desert (BRD) is a semi-arid area covered by a series of lava beds, playa, and alkali flats, located in the far northwestern Nevada section of the Great Basin with a lakebed that is a dry remnant of the prehistoric Lake Lahontan. Predominant natural aerosol sources in the semi-arid environments come from windblown mineral dust [69]. Large quantities of wildfire-generated biomass burning aerosols in the east-northeast direction during the California fire season (May-October) are another primary aerosol source affecting the local air pollution [70]. In addition to the effects of dust episodes and wildfire smoke, relatively high particulate levels in the BRD region can result from the annual Burning Man event held in September.

The high surface reflectance over arid and semi-arid regions produces extensive nonrandom missing grid-specific satellite $A O D$ values as they are quality flagged, which impairs the spatial-temporal coverage in observing local aerosols globally. Another challenge is $A O D$ artifacts over very bright surfaces. For example, monthly averages of columnar $A O D$ in the BRD region during the 2012 summer were abnormally high $(\sim 0.7)$ at $550 \mathrm{~nm}$ in the absence of anthropogenic or wildfire aerosol emissions [37]. This indicates that when the desert surface has an albedo value within the 0.4-0.5 range [38] that is smaller than the CSA ( 0.55) and the corresponding scattering angle $<100^{\circ}$ [42], the underestimated satellite-retrieved surface albedo leads to unrealistically high $A O D$ values over the BRD.

To illustrate the importance of quantifying $A O D$ retrieval uncertainties associated with errors in $A, S S A$, and $g$, we use our 1-D model with real values from the BRD as a case study. Based on Boehmler et al. (2018) [38], the dry lake beds of the BRD have an actual albedo value of $\sim 0.59$ over non-road areas and $\sim 0.56$ over road locations for the wavelength range of 770-900 nm. Uncertainties in measured versus satellite estimated albedo propagate through to uncertainties in the satellite retrieved $A O D$. The albedo retrievals from Land Satellite 7 Enhanced Thematic Mapper Plus (Landsat-7 ETM+) manufactured by Lockheed Martin Space Systems in Denver, CO are lower than the measured albedometer values by $13.56 \%$ for non-road areas and $16.07 \%$ for road areas. $A O D$ errors associated with uncertainties in surface albedo estimates over the BRD region can be explained by the closeness of the surface albedo to the CSA (0.36) for desert (mineral dust) aerosols. According to Equation (11a), the deviation of $A O D(\triangle A O D$, also known as $A O D$ error) due to the difference in surface albedo is 1.16 when $\mathrm{A} \sim 0.59$ for the non-road surface, assuming the aerosols are windblown dust. Extending this to calculate the $A O D$ errors for a polluted air mass transported over the $\mathrm{BRD}$, the deviation of $A O D$ is 0.51 when $A \sim 0.56$ over the road surface. The $A O D$ uncertainty associated with uncertainties in $A$ decreases for the polluted air mass scenario because the CSA decreases, compared to mineral dust aerosols, and is significantly lower than the real albedo value. Physically, the CSA for the polluted scenario is less than the mineral dust because the aerosols are more absorbing, which, in turn, reduces the satellite $A O D$ bias over deserts. We make additional calculations to determine uncertainties in $A O D$ retrievals associated with the sensitivity of $A O D$ to single scattering albedo and asymmetry parameter. For single scattering albedo, $\frac{\partial A O D}{\partial S S A}$ is 0.52 for desert aerosols around non-road areas but increases to 0.65 for continental polluted aerosols around road areas. For asymmetry parameter, $\frac{\partial A O D}{\partial g}$ is -0.03 for desert aerosols above non-road areas but tends to -0.04 for continental polluted aerosols above road areas. This indicates that selecting an inaccurate aerosol type from the LUT by mistake propagates the errors in $S S A$ and $g$ through to the retrieved $A O D$. The $A O D$ uncertainties associated with each of these physical parameters are not insignificant. For mineral dust with a retrieved $A O D$ value of 0.03 (approximate $870 \mathrm{~nm} A O D$ from Figure 2) above a non-road location and a polluted air mass with a retrieved $A O D$ value of 0.1 above a road location, both have uncertainties far greater than $100 \%$.

In light of the discussion above, the sign of the $A O D$ retrieval error depends on the wavelength of the retrieval where it switches from negative to positive due to the actual albedo becoming larger than the CSA at the higher bands. Also, the low background aerosol concentrations in desert regions render the $A O D$ uncertainty unreasonably large 
for any type of aerosol. Retrieving $A O D$ for bright (e.g., mineral dust) aerosols over bright surfaces (e.g., deserts) is a more complicated process than retrieving $A O D$ for dark (e.g., black carbon) aerosols over regions with high reflectance. Sparse AERONET sites in the remote areas of the western U.S. make it impossible to quantify the satellite $A O D$ retrieval error in these areas. Thus, it is difficult to account for these errors in the current satellite $A O D$ products, except for multiangle observations (e.g., MISR, ATSR-2, and AATSR) which have been shown to be less susceptible to CSA-related retrieval degeneracies [71,72]. Consequently, the sensitivity of $A O D$ to the parameters $A, S S A$, and $g$ are needed in future satellite algorithm development to investigate uncertainties in $A O D$ retrievals over bright surfaces, especially semi-arid environments across the globe.

\section{Conclusions}

Previous studies mainly focused on applying the critical reflectance derived from satellite data to retrieve aerosol absorption [45-48]. Seidel and Popp (2012) [42] summarized the relationships of CSA with various parameters such as SSA, scattering angle, and wavelength. Our goal is to complement these investigations by estimating the satellite $A O D$ uncertainty based on a 1-D radiative transfer model and determining the CSA, CSSA, and CAP using this model. The sensitivity analysis of TOA reflectance as a function of surface albedo, single scattering albedo, and asymmetry parameter to $A O D$ as well as the resulting CSA, CSSA, and CAP is comprehensively discussed through physical examples of each parameter and its impact on $A O D$ retrievals.

This study concludes that satellite $A O D$ retrievals under conditions when $A, S S A$, or $g$ are close to the CSA, CSSA, or CAP would give rise to large errors due to the observed TOA radiance's low sensitivity to the retrieved quantity. In such a case, we find that even small inaccuracies of the model-based or measurement-based estimated surface albedo and aerosol optical properties lead to large $A O D$ retrieval errors. When surface albedo is smaller than the CSA, an overestimation of surface albedo ( $+5 \%)$ leads to the underestimated retrieved $A O D$ and thus a positive retrieval error $(\triangle A O D>0)$. The same $A O D$ pattern holds when the single scattering albedo or asymmetry parameter is larger than the critical value (CSSA or CAP) with an overestimation of single scattering albedo or asymmetry parameter $(+5 \%)$. These critical values would be great supplements to satellite aerosol retrieval algorithms by considering the $A O D$ retrieval accuracy given different aerosol types over multiple surfaces. Results in this paper also reaffirm that the retrieval error in $A O D$ becomes negligible for two cases: (1) strongly absorbing aerosols with high surface reflectance; (2) weakly absorbing aerosols over dark land surfaces. The methods provided in this paper can be used for the development and refinement of satellitebased $A O D$ estimation using the CSA, CSSA, and CAP concepts. In particular, the quick, simplified model shown here can be used to target which improvements to make in the retrieval algorithms and provide an initial estimate of the associated $A O D$ uncertainty.

Establishing a simple and fast radiative transfer model of atmospheric aerosols to estimate $A O D$ uncertainties not only facilitates data use, but it also better informs scientific users of the $A O D$ retrieval quality by establishing a method to quantify uncertainties. In the future, additional sensitivity analyses for the analytical solution of the TOA reflectance as a function of $A O D$ needs to be done with a variety of parameters (e.g., surface albedo, single scattering albedo, asymmetry parameter, wavelength, solar zenith angle, viewing zenith angle). The uncertainty analysis of satellite $A O D$ in this paper is useful but can only describe limited aspects of the uncertainty-the 'unknowns' that are known and quantifiable. More complex systematic errors in the model approximations and assumptions can be incorporated in an updated version of the radiative transfer model.

Supplementary Materials: The following are available online at https:/ / www.mdpi.com/2072-429 2/13/3/344/s1, Figure S1: Derivative of TOA reflectance with respect to $A O D$ as functions of surface albedo, single scattering albedo, and asymmetry parameter for different aerosol models. 
Author Contributions: Conceptualization: W.P.A., H.A.H. and J.H.; Model development: W.P.A., J.H., H.A.H. and J.C.B.; Data visualization and analysis: J.H.; Writing-Original draft preparation: J.H.; Writing-Review and Editing: J.H., H.A.H., W.P.A. and J.C.B. All authors have read and agreed to the published version of the manuscript.

Funding: This work is supported in part by the U.S. National Science Foundation under grant number IIS-1838024 (H.A.H.) as part of the NSF BIGDATA program.

Acknowledgments: The authors would like to thank the NASA AERONET team for providing free access to the aerosol measurements used in this paper.

Conflicts of Interest: The authors declare no conflict of interest.

\section{References}

1. McCormick, R.A.; Ludwig, J.H. Climate Modification by Atmospheric Aerosols. Science 1967, 156, 1358-1359. [CrossRef] [PubMed]

2. Charlson, R.J.; Pilat, M.J. Climate: The Influence of Aerosols. J. Appl. Meteorol. 1969, 8, 1001-1002. [CrossRef]

3. Mitchell, J.M., Jr. The effect of atmospheric aerosols on climate with special reference to temperature near the earth's surface. J. Appl. Meteorol. 1971, 10, 703-714. [CrossRef]

4. Levy, H.; Horowitz, L.W.; Schwarzkopf, M.D.; Ming, Y.; Golaz, J.-C.; Naik, V.; Ramaswamy, V. The roles of aerosol direct and indirect effects in past and future climate change. J. Geophys. Res. Atmos. 2013, 118, 4521-4532. [CrossRef]

5. Haywood, J.; Boucher, O. Estimates of the direct and indirect radiative forcing due to tropospheric aerosols: A review. Rev. Geophys. 2000, 38, 513-543. [CrossRef]

6. Penner, J.E.; Andreae, M.; Annegarn, H.; Barrie, L.; Feichter, J.; Hegg, D.; Jayaraman, A.; Leaitch, R.; Murphy, D.; Nganga, J.; et al. Aerosols, their direct and indirect effects. In Climate Change 2001: The Scientific Basis, Report to Intergovernmental Panel on Climate Change from the Scientific Assessment Working Group (WGI); Cambridge University Press: Cambridge, UK; New York, NY, USA, 2001; pp. 289-348.

7. Intergovernmental Panel On Climate Change (IPCC) (Ed.) Climate Change 2013: The Physical Science Basis: Working Group I Contribution to the Fifth Assessment Report of the Intergovernmental Panel on Climate Change; Cambridge University Press: Cambridge, UK; New York, NY, USA, 2014; pp. 31-116.

8. Pilinis, C.; Pandis, S.N.; Seinfeld, J.H. Sensitivity of direct climate forcing by atmospheric aerosols to aerosol size and composition. J. Geophys. Res. Atmos. 1995, 100, 18739-18754. [CrossRef]

9. Jacobson, M.Z. Global direct radiative forcing due to multicomponent anthropogenic and natural aerosols. J. Geophys. Res. Atmos. 2001, 106, 1551-1568. [CrossRef]

10. Kaufman, Y.J.; Tanré, D.; Boucher, O. A satellite view of aerosols in the climate system. Nature 2002, 419, 215-223. [CrossRef]

11. Liao, H.; Seinfeld, J.H. Radiative forcing by mineral dust aerosols: Sensitivity to key variables. J. Geophys. Res. Atmos. 1998, 103, 31637-31645. [CrossRef]

12. Chin, M.; Kahn, R.A.; Swartz, S.E. (Eds.) Atmospheric aerosol properties and climate impacts. In U.S. Climate Change Science Program. Synthesis and Assessment Product 2.3; U.S. Climate Change Science Program and Subcommittee on Global Change Research, National Aeronautics and Space Administration: Washington, DC, USA, 2009; p. 115.

13. Pósfai, M.; Buseck, P.R. Nature and Climate Effects of Individual Tropospheric Aerosol Particles. Annu. Rev. Earth Planet. Sci. 2010, 38, 17-43. [CrossRef]

14. Schulz, M.; Textor, C.; Kinne, S.; Balkanski, Y.; Bauer, S.; Berntsen, T.; Berglen, T.; Boucher, O.; Dentener, F.; Guibert, S.; et al. Radiative forcing by aerosols as derived from the AeroCom present-day and pre-industrial simulations. Atmos. Chem. Phys. 2006, 6, 5225-5246. [CrossRef]

15. Myhre, G.; Berglen, T.F.; Johnsrud, M.; Hoyle, C.; Berntsen, T.K.; Christopher, S.A.; Fahey, D.W.; Isaksen, I.S.A.; Jones, T.A.; Kahn, R.A.; et al. Modelled radiative forcing of the direct aerosol effect with multi-observation evaluation. Atmos. Chem. Phys. 2009, 9 , 1365-1392. [CrossRef]

16. Ma, X.; Yu, F.; Luo, G. Aerosol direct radiative forcing based on GEOS-Chem-APM and uncertainties. Atmos. Chem. Phys. 2012, 12, 5563-5581. [CrossRef]

17. Myhre, G.; Samset, B.H.; Schulz, M.; Balkanski, Y.; Bauer, S.; Berntsen, T.K.; Bian, H.; Bellouin, N.; Chin, M.; Diehl, T.; et al. Radiative forcing of the direct aerosol effect from AeroCom Phase II simulations. Atmos. Chem. Phys. 2013, 13, $1853-1877$. [CrossRef]

18. Huang, X.; Song, Y.; Zhao, C.; Cai, X.; Zhang, H.; Zhu, T. Direct Radiative Effect by Multicomponent Aerosol over China. J. Clim. 2015, 28, 3472-3495. [CrossRef]

19. Chung, C.E.; Ramanathan, V.; Kim, D.; Podgorny, I.A. Global anthropogenic aerosol direct forcing derived from satellite and ground-based observations. J. Geophys. Res. Atmos. 2005, 110. [CrossRef]

20. Bellouin, N.; Boucher, O.; Tanre, D.; Dubovik, O. Aerosol absorption over the clear-sky oceans deduced from POLDER-1 and AERONET observations. Geophys. Res. Lett. 2003, 30. [CrossRef] 
21. Bellouin, N.; Boucher, O.; Haywood, J.; Reddy, M.S. Global estimate of aerosol direct radiative forcing from satellite measurements. Nat. Cell Biol. 2005, 438, 1138-1141. [CrossRef]

22. Bellouin, N.; Jones, A.; Haywood, J.; Christopher, S.A. Updated estimate of aerosol direct radiative forcing from satellite observations and comparison against the Hadley Centre climate model. J. Geophys. Res. Atmos. 2008, 113. [CrossRef]

23. Kato, S.; Rose, F.G.; Sun-Mack, S.; Miller, W.F.; Chen, Y.; Rutan, D.A.; Stephens, G.L.; Loeb, N.G.; Minnis, P.; Wielicki, B.A.; et al. Improvements of top-of-atmosphere and surface irradiance computations with CALIPSO-, CloudSat-, and MODIS-derived cloud and aerosol properties. J. Geophys. Res. Atmos. 2011, 116. [CrossRef]

24. Verma, S.; Prakash, D.; Soni, M.; Ram, K. Atmospheric Aerosols Monitoring: Ground and Satellite-Based Instruments. In Advances in Environmental Monitoring and Assessment; IntechOpen: London, UK, 2019; pp. 67-80.

25. Chylek, P.; Henderson, B.; Mishchenko, M.I. Aerosol radiative forcing and the accuracy of satellite aerosol optical depth retrieval. J. Geophys. Res. Atmos. 2003, 108. [CrossRef]

26. Chu, D.A.; Kaufman, Y.J.; Zibordi, G.; Chern, J.D.; Mao, J.; Li, C.; Holben, B.N. Global monitoring of air pollution over land from the Earth Observing System-Terra Moderate Resolution Imaging Spectroradiometer (MODIS). J. Geophys. Res. Atmos. 2003, 108. [CrossRef]

27. Engel-Cox, J.A.; Holloman, C.H.; Coutant, B.W.; Hoff, R.M. Qualitative and quantitative evaluation of MODIS satellite sensor data for regional and urban scale air quality. Atmos. Environ. 2004, 38, 2495-2509. [CrossRef]

28. Boucher, O.; Tanre, D. Estimation of the aerosol perturbation to the Earth's Radiative Budget over oceans using POLDER satellite aerosol retrievals. Geophys. Res. Lett. 2000, 27, 1103-1106. [CrossRef]

29. Myhre, G. Consistency Between Satellite-Derived and Modeled Estimates of the Direct Aerosol Effect. Science 2009, 325, 187-190. [CrossRef] [PubMed]

30. Kassianov, E.I.; Flynn, C.J.; Ackerman, T.P.; Barnard, J.C. Aerosol single-scattering albedo and asymmetry parameter from MFRSR observations during the ARM Aerosol IOP 2003. Atmos. Chem. Phys. 2007, 7, 3341-3351. [CrossRef]

31. Lee, J.; Hsu, N.C.; Sayer, A.M.; Bettenhausen, C.; Yang, P. AERONET-Based Nonspherical Dust Optical Models and Effects on the VIIRS Deep Blue/SOAR Over Water Aerosol Product. J. Geophys. Res. Atmos. 2017, 122, 10-384. [CrossRef]

32. Kinne, S.; Schulz, M.; Textor, C.; Guibert, S.; Balkanski, Y.; Bauer, S.E.; Berntsen, T.; Berglen, T.F.; Boucher, O.; Chin, M.; et al. An AeroCom initial assessment-Optical properties in aerosol component modules of global models. Atmos. Chem. Phys. 2006, 6, 1815-1832. [CrossRef]

33. Wong, J.; Li, Z. Retrieval of Optical Depth for Heavy Smoke Aerosol Plumes: Uncertainties and Sensitivities to the Optical Properties. J. Atmos. Sci. 2002, 59, 250-261. [CrossRef]

34. Remer, L.A.; Kaufman, Y.J.; Tanré, D.; Mattoo, S.; Chu, D.A.; Martins, J.V.; Li, R.R.; Ichoku, C.; Levy, R.C.; Kleidman, R.G.; et al. The MODIS Aerosol Algorithm, Products, and Validation. J. Atmos. Sci. 2005, 62, 947-973. [CrossRef]

35. Holben, B.; Eck, T.; Slutsker, I.; Tanré, D.; Buis, J.; Setzer, A.; Vermote, E.; Reagan, J.; Kaufman, Y.; Nakajima, T.; et al. AERONET—A Federated Instrument Network and Data Archive for Aerosol Characterization. Remote Sens. Environ. 1998, 66, 1-16. [CrossRef]

36. Islam, M.N.; Ali, M.A.; Islam, M.M. Spatiotemporal Investigations of Aerosol Optical Properties Over Bangladesh for the Period 2002-2016. Earth Syst. Environ. 2019, 3, 563-573. [CrossRef]

37. Loría-Salazar, S.M.; Holmes, H.A.; Arnott, W.P.; Barnard, J.C.; Moosmüller, H. Evaluation of MODIS columnar aerosol retrievals using AERONET in semi-arid Nevada and California, USA., during the summer of 2012. Atmos. Environ. 2016, 144, 345-360. [CrossRef]

38. Boehmler, J.M.; Loría-Salazar, S.M.; Stevens, C.; Long, J.D.; Watts, A.C.; Holmes, H.A.; Barnard, J.; Arnott, W.P. Development of a Multispectral Albedometer and Deployment on an Unmanned Aircraft for Evaluating Satellite Retrieved Surface Reflectance over Nevada's Black Rock Desert. Sensors 2018, 18, 3504. [CrossRef]

39. Kaufman, Y.J.; Wald, A.E.; Remer, L.A.; Gao, B.-C.; Li, R.-R.; Flynn, L. The MODIS 2.1-/spl mu/m channel-correlation with visible reflectance for use in remote sensing of aerosol. IEEE Trans. Geosci. Remote Sens. 1997, 35, 1286-1298. [CrossRef]

40. Vincent, D.A. Aerosol Optical Depth Retrievals from High-Resolution Commercial Satellite Imagery over Areas of High Surface Reflectance. Ph.D. Thesis, Naval Postgraduate School, Department of Meteorology, Monterey, CA, USA, 2006.

41. Hsu, N.C.; Tsay, S.-C.; King, M.D.; Herman, J.R. Aerosol Properties Over Bright-Reflecting Source Regions. IEEE Trans. Geosci. Remote Sens. 2004, 42, 557-569. [CrossRef]

42. Seidel, F.C.; Popp, C. Critical surface albedo and its implications to aerosol remote sensing. Atmos. Meas. Tech. 2012, 5, 1653-1665. [CrossRef]

43. Fraser, R.S.; Kaufman, Y.J. The Relative Importance of Aerosol Scattering and Absorption in Remote Sensing. IEEE Trans. Geosci. Remote Sens. 1985, 23, 625-633. [CrossRef]

44. Kaufman, Y.J. Satellite sensing of aerosol absorption. J. Geophys. Res. Atmos. 1987, 92, 4307-4317. [CrossRef]

45. Castanho, A.D.; Martins, J.V.; Artaxo, P. MODIS Aerosol Optical Depth Retrievals with high spatial resolution over an Urban Area using the Critical Reflectance. J. Geophys. Res. 2008, 113, D02201. [CrossRef]

46. Zhu, L.; Martins, J.V.; Remer, L.A. Biomass burning aerosol absorption measurements with MODIS using the critical reflectance method. J. Geophys. Res. Atmos. 2011, 116. [CrossRef]

47. Wells, K.C.; Martins, J.V.; Remer, L.A.; Kreidenweis, S.M.; Stephens, G.L. Critical reflectance derived from MODIS: Application for the retrieval of aerosol absorption over desert regions. J. Geophys. Res. Atmos. 2012, 117. [CrossRef] 
48. Kim, M.; Kim, J.; Wong, M.S.; Yoon, J.; Lee, J.; Wu, N.; Chan, P.W.; Nichol, J.E.; Chung, C.-Y.; Ou, M.-L. Improvement of aerosol optical depth retrieval over Hong Kong from a geostationary meteorological satellite using critical reflectance with background optical depth correction. Remote Sens. Environ. 2014, 142, 176-187. [CrossRef]

49. Seidel, F.C.; Kokhanovsky, A.; Schaepman, M. Fast retrieval of aerosol optical depth and its sensitivity to surface albedo using remote sensing data. Atmos. Res. 2012, 116, 22-32. [CrossRef]

50. Ceamanos, X.; Moparthy, S.; Carrer, D.; Seidel, F.C. Assessing the Potential of Geostationary Satellites for Aerosol Remote Sensing Based on Critical Surface Albedo. Remote Sens. 2019, 11, 2958. [CrossRef]

51. Ichoku, C.; Chu, D.A.; Mattoo, S.; Kaufman, Y.J.; Remer, L.A.; Tanre, D.; Slutsker, I.; Holben, B.N. A spatio-temporal approach for global validation and analysis of MODIS aerosol products. Geophys. Res. Lett. 2002, 29. [CrossRef]

52. Levy, R.C.; Remer, L.A.; Kleidman, R.G.; Mattoo, S.; Ichoku, C.; Kahn, R.; Eck, T.F. Global evaluation of the Collection 5 MODIS dark-target aerosol products over land. Atmos. Chem. Phys. 2010, 10, 10399-10420. [CrossRef]

53. Hyer, E.J.; Reid, J.S.; Zhang, J. An over-land aerosol optical depth data set for data assimilation by filtering, correction, and aggregation of MODIS Collection 5 optical depth retrievals. Atmos. Meas. Tech. 2011, 4, 379-408. [CrossRef]

54. Carboni, E.; Thomas, G.E.; Sayer, A.; Siddans, R.A.; Poulsen, C.; Grainger, R.G.; Ahn, C.; Antoine, D.J.; Bevan, S.; Braak, R.; et al. Intercomparison of desert dust optical depth from satellite measurements. Atmos. Meas. Tech. 2012, 5, 1973-2002. [CrossRef]

55. Povey, A.C.; Grainger, R.G. Known and unknown unknowns: Uncertainty estimation in satellite remote sensing. Atmos. Meas. Tech. 2015, 8, 4699-4718. [CrossRef]

56. Knapp, K.R.; Haar, T.H.V.; Kaufman, Y.J. Aerosol optical depth retrieval from GOES-8: Uncertainty study and retrieval validation over South America. J. Geophys. Res. Atmos. 2002, 107. [CrossRef]

57. Sayer, A.M.; Hsu, N.C.; Bettenhausen, C.; Jeong, M.-J. Validation and uncertainty estimates for MODIS Collection 6 “Deep Blue” aerosol data. J. Geophys. Res. Atmos. 2013, 118, 7864-7872. [CrossRef]

58. Kokhanovsky, A.A. Variability of the Phase Function of Atmospheric Aerosols at Large Scattering Angles. J. Atmos. Sci. 1998, 55, 314-320. [CrossRef]

59. Kokhanovsky, A.A. Analytical solutions of multiple light scattering problems: A review. Meas. Sci. Technol. 2002, 13, 233-240. [CrossRef]

60. Zeng, Z.-C.; Xu, F.; Natraj, V.; Pongetti, T.J.; Shia, R.-L.; Zhang, Q.; Sander, S.P.; Yung, Y.L. Remote sensing of angular scattering effect of aerosols in a North American megacity. Remote Sens. Environ. 2020, 242, 111760. [CrossRef]

61. Arras, K.O. An Introduction to Error Propagation: Derivation, Meaning and Examples of Equation CY = FX CX FXT; Swiss Federal Institute of Technology Lausann: Lausanne, Switzerland, 1998; EPFL-ASL-TR-98-01 R3.

62. D'Almeida, G.A.; Koepke, P.; Shettle, E.P. Atmospheric Aerosols: Global Climatology and Radiative Characteristics; A Deepak Pub: Hampton, VA, USA, 1991.

63. Levoni, C.; Cervino, M.; Guzzi, R.; Torricella, F. Atmospheric aerosol optical properties: A database of radiative characteristics for different components and classes. Appl. Opt. 1997, 36, 8031-8041. [CrossRef] [PubMed]

64. Dubovik, O.; Holben, B.; Eck, T.F.; Smirnov, A.; Kaufman, Y.J.; King, M.D.; Tanré, D.; Slutsker, I. Variability of Absorption and Optical Properties of Key Aerosol Types Observed in Worldwide Locations. J. Atmos. Sci. 2002, 59, 590-608. [CrossRef]

65. Levy, R.C.; Remer, L.A.; Dubovik, O. Global aerosol optical properties and application to Moderate Resolution Imaging Spectroradiometer aerosol retrieval over land. J. Geophys. Res. Atmos. 2007, 112. [CrossRef]

66. Curci, G.; Hogrefe, C.; Bianconi, R.; Im, U.; Balzarini, A.; Baro, R.; Brunner, D.; Forkel, R.; Giordano, L.; Hirtl, M.; et al. Uncertainties of simulated aerosol optical properties induced by assumptions on aerosol physical and chemical properties: An AQMEII-2 perspective. Atmos. Environ. 2015, 115, 541-552. [CrossRef]

67. Hess, M.; Koepke, P.; Schult, I. Optical Properties of Aerosols and Clouds: The Software Package OPAC. Bull. Am. Meteorol. Soc. 1998, 79, 831-844. [CrossRef]

68. Sayer, A.M.; Munchak, L.A.; Hsu, N.C.; Levy, R.C.; Bettenhausen, C.; Jeong, M.J. MODIS Collection 6 aerosol products: Comparison between Aqua's e-Deep Blue, Dark Target, and "merged" data sets, and usage recommendations. J. Geophys. Res. Atmos. 2014, 119, 13-965. [CrossRef]

69. Provençal, S.; Kishcha, P.; Da Silva, A.M.; Elhacham, E.; Alpert, P. AOD distributions and trends of major aerosol species over a selection of the world's most populated cities based on the 1st version of NASA's MERRA Aerosol Reanalysis. Urban Clim. 2017, 20, 168-191. [CrossRef] [PubMed]

70. Peterson, D.A.; Hyer, E.J.; Campbell, J.R.; Fromm, M.D.; Hair, J.W.; Butler, C.F.; Fenn, M.A. The 2013 Rim Fire: Implications for Predicting Extreme Fire Spread, Pyroconvection, and Smoke Emissions. Bull. Amer. Meteor. Soc. 2015, 96, 229-247. [CrossRef]

71. Martonchik, J.V.; Diner, D. Retrieval of aerosol optical properties from multi-angle satellite imagery. IEEE Trans. Geosci. Remote Sens. 1992, 30, 223-230. [CrossRef]

72. Diner, D.J.; Braswell, B.H.; Davies, R.; Gobron, N.; Hu, J.; Jin, Y.; Kahn, R.A.; Knyazikhin, Y.; Loeb, N.; Muller, J.-P.; et al. The value of multiangle measurements for retrieving structurally and radiatively consistent properties of clouds, aerosols, and surfaces. Remote Sens. Environ. 2005, 97, 495-518. [CrossRef] 